\title{
ESCA and TOF-SIMS Study on Oxidised and Reduced Polypyrrole-Poly(Vinylsulfonic Acid, Sodium Salt) Films Synthesized on Ti Electrodes
}

\author{
Lay-Lian Teo, ${ }^{1}$ Sau-Leng Sin, ${ }^{2}$ and Chee-Yan Chan ${ }^{3}$ \\ ${ }^{1}$ Faculty of Engineering and Technology, Melaka Campus, Multimedia University, Jalan Ayer Keroh Lama, Melaka 75450, Malaysia \\ ${ }^{2}$ Dynea Singapore Pte Ltd., Apt Blk 939, Jurong West, St 91, no. 08-415, Singapore 640939 \\ ${ }^{3}$ Chemindus Sdn. Bhd., Jalan Selat Selatan 6, Landpac Industrial Park, Port Klang, Selangor 42000, Malaysia
}

Correspondence should be addressed to Lay-Lian Teo, llteo@mmu.edu.my

Received 1 October 2009; Revised 1 March 2010; Accepted 3 March 2010

Academic Editor: Ping Xiao

Copyright (C) 2010 Lay-Lian Teo et al. This is an open access article distributed under the Creative Commons Attribution License, which permits unrestricted use, distribution, and reproduction in any medium, provided the original work is properly cited.

\begin{abstract}
We had previously reported on a surface analysis investigation of electrochemically synthesized, both oxidized and reduced, polypyrrole-poly-4-styrenesulfonate free-standing films (Sin et al., 2000). We apply the same techniques that we used earlier (Sin et al., 2000) to study polypyrrole-poly(vinylsulfonic acid, sodium salt) (PPy-PVS) free-standing films. Electron Spectroscopy for Chemical Analysis (ESCA) and Time of Flight Secondary Ion Mass Spectrometry (TOF-SIMS) were used in the surface morphology study of oxidized and reduced PPy-PVS composite films. ESCA spectra seem to indicate that the CO and C-OH structures reduced to $\mathrm{C}-\mathrm{C}$ bonds during the reduction process and also seem to reveal interesting charge transfer behavior, namely. $\mathrm{NH}^{+}$and $\mathrm{N}-\mathrm{H}$ bonds to imine group $(\mathrm{N}=\mathrm{C})$ at reduced PPy-PVS free standing films. Furthermore, TOF-SIMS ion mapping also provided some interesting surface distribution of elements on PPy-PVS composite films. A comparison of surface conductivities between the two sides of both types of films was made,with conductivity measurements being carried out using the four-point probe technique.
\end{abstract}

\section{Introduction}

Polypyrrole (PPy), one of the most extensively studied conducting polymers, has been recognized for its long-term conductivity stability and ability in forming homopolymers or composites with optimal mechanical properties with conductivities up to $1000 \mathrm{~S} / \mathrm{cm}$ which approach the conductivity of metals $[1,2]$. PPy is used in numerous technological applications, such as in the fabrication of molecular electronic devices [3], electrodes for solid-state batteries [4], as solid electrolytes for capacitors [5], electromagnetic interference-shielding materials $[6]$, ionsensors $[7,8]$, and ionexchangers for waste-water treatment $[9,10]$. Gade et al. [11] reported the immobilization of glucose oxidase on a PPy-PVS composite film that was used as a biosensor to determine glucose and had characterized the composite films using electrochemical techniques, electrical conductivity measurements, UV-Vis spectroscopy, Fourier Transform IR spectroscopy, and Scanning Electron Microscopy.
Gambhir et al. [12] reported the adsorption of DNA onto PPy-PVS films which were also characterized by similar studies. Because of the many potentially useful applications of PPy-PVS composite films [11, 12], it is desirable to investigate further the surface morphology, conductivity, and composition of such oxidized and reduced conducting polymer films. ESCA has long been an important analytical tool for semiquantitative elemental analysis of surfaces (10$20 \mathrm{~nm}$ depth) of polypyrrole composite materials [1, 13-19]. Ge et al. [13], using X-ray photoelectron spectroscopy, had observed that the original positive charges on polypyrrole $\left(-\mathrm{NH}^{+}-\right)$were mostly replaced by $-\mathrm{NH}-$ and $-\mathrm{CH}-$ and were oxidized to $-\mathrm{COH}-$ and subsequently changed into $-\mathrm{C}=\mathrm{O}$ during overoxidation.

We had investigated the surface features of PPy-PSS in our earlier work [1]. The present investigation focused on free-standing PPy-PVS films which were peeled off from titanium plate electrodes after electrosynthesis at oxidizing and reducing potentials. The morphology of the two surfaces 
TABLE 1: The surface conductivity at the electrolyte and electrode sides versus different concentrations of pyrrole on the oxidised PPy-PVS composite films.

\begin{tabular}{lcccc}
\hline \multirow{2}{*}{ Concentration of pyrrole $\left(\mathrm{mole} \mathrm{kg}^{-1}\right)$} & \multirow{2}{*}{ Thickness $(\mathrm{mm})$} & \multicolumn{2}{c}{ Surface conductivity $\left(\mathrm{Scm}^{-1}\right)$} & \multirow{2}{*}{ Percentage of difference $(\%)$} \\
\hline 0.1 & & Electrolyte side & Electrolyte side & \\
0.2 & 0.0311 & $0.01838 \pm 0.001$ & $0.01838 \pm 0.001$ & 0.19 \\
0.3 & 0.0208 & $0.02380 \pm 0.002$ & $0.02380 \pm 0.002$ & 0.42 \\
0.4 & 0.0210 & $0.04110 \pm 0.002$ & $0.04110 \pm 0.002$ & 0.24 \\
0.5 & 0.0219 & $0.05460 \pm 0.002$ & $0.05460 \pm 0.002$ & 0.18 \\
\hline
\end{tabular}

of free-standing PPy-PVS films was studied and their surface features were characterised using electrical conductivity measurements, ESCA, and TOF-SIMS. PPy-PVS films were electrochemically synthesized with various concentrations of poly(vinylsulfonic acid, sodium salt) and pyrrole in aqueous solutions and the surface conductivities of both sides of each film were determined using the four-point probe technique. ESCA was used to study the charge transfer behaviour of the deprotonated pyrrolium nitrogen $\left(\mathrm{NH}^{+}\right)$and $\mathrm{N}-\mathrm{H}$ bonds with that of the imine nitrogen $(\mathrm{N}=\mathrm{C})$, and the $\mathrm{CO}$ with $\mathrm{C}-\mathrm{OH}$ structures to $\mathrm{C}-\mathrm{C}$ bonds at oxidizing and reducing potentials of polypyrrole composite films used. TOF-SIMS images would reveal interesting structural features of surface morphology of the PPy-PVS films prepared in this work.

\section{Experimental}

2.1. Chemicals and Reagents. Titanium foil $(0.127 \mathrm{~mm}$ thick, 99.7\% pure, from Aldrich Chemical Co. Inc.) was used as anode material. Platinised titanium gauze from Morgett Electrochemicals Ltd., UK was used as counter-electrode material. Pyrrole (Fluka Chemical) was distilled under reduced pressure and stored under oxygen-free nitrogen in darkened flasks. All the films listed in Table 1 were prepared from analytical grade poly(vinylsulfonic acid, sodium salt) from Aldrich Chemical Co. Inc. and used without further purification. Doublydistilled water was used for solution preparations.

2.2. Instruments. The electropolymerization cell consisted simply of a flag-shaped $\mathrm{Ti}$ anode plate and two rectangular pieces of platinised $\mathrm{Ti}$ gauze cathodes, placed on either sides of the anode plate, in a $150 \mathrm{~cm}^{3}$ beaker containing the forming solution. An $\mathrm{Ag} / \mathrm{AgCl} / \mathrm{KCl}$ (aqueous, saturated)/ceramic junction electrode was used as reference electrode and magnetic stirring was used. An EG\&G PAR Model 363 Potentiostat-Galvanostat was used for current or potential control, together with a Keithley Model 197 Digital Multimeter.

ESCA data were obtained using a VG Microtech Spectrometer with a dual anode $(\mathrm{Mg} / \mathrm{Al}) \mathrm{X}$-ray source and Clam $2 / 4 \mathrm{~V}$ triple channeltron analyser (Fissons Instruments). VG Microtech's VGX 900I data system was used for data acquisition and analysis. $\mathrm{Mg} \mathrm{K}_{\alpha}$ radiation at $1253.6 \mathrm{eV}$ was used for all samples studied. TOF-SIMS spectra, secondary electron (SE) images, and secondary ion (SI) maps were obtained using a Cameca TOF-SIMS IV system with a Ga primary ion gun. Raster area for ionmapping was $500 \mu \mathrm{m}$ $\times 500 \mu \mathrm{m}$ and raster resolution was at 128 pixel $\times 128$ pixel which yielded a lateral resolution of about $4 \mu \mathrm{m}$. UHV in both the XPS and TOF-SIMS sample chambers, which were interconnected with an interlocking gate, was maintained at $10^{-8}-10^{-9} \mathrm{mBar}$. ESCA preceded TOF-SIMS analysis for every sample.

\subsection{Electrochemical Preparation and Surface Characteriza-} tions of PPY-PVS Composite Films. PPy-PVS composite films were prepared from various $0.1 \mathrm{~mol} \mathrm{~kg}^{-1}$ poly(vinylsulfonic acid, sodium salt) aqueous solutions containing 0.1 to $0.5 \mathrm{~mol} \mathrm{~kg}^{-1}$ of pyrrole monomer. Each film was electrochemically deposited on a titanium anode plate at a constant current of $50 \mathrm{~mA} \mathrm{~cm}^{-2}$ and recorded in range of $1.4-2.3 \mathrm{~V}$ (ref. Ag/AgCl) potential for 30 minutes. A constant potential of $-1.0 \mathrm{~V}$ (ref. $\mathrm{Ag} / \mathrm{AgCl}$ ) was applied for a further 30 minutes to reduce certain films in the same forming solution immediately after film formation. All oxidized and reduced films were washed several times with $\mathrm{d}$-d water, peeled off from the Ti substrate, and washed thoroughly again before leaving to dry overnight in a clean oven set at $50^{\circ} \mathrm{C}$, after which they were stored in vacuum desiccators. The fourpoint probe technique [20] was used for surface conductivity determinations, averaged over 4-6 different positions on each surface. The 4-point probe was constructed [9] from an eight-pin I.C. socket with uniform gold-plated pins, and four equally spaced pins were connected to the galvanostat and the digital multimeter in the required manner [20]. Film thickness was measured using a Mitutoyo micrometer, with a precision of $\pm 1 \mathrm{~nm}$. Free standing oxidized and reduced films formed from $0.1 \mathrm{~mol} \mathrm{~kg}^{-1}$ pyrrole and $0.1 \mathrm{~mol} \mathrm{~kg}^{-1}$ poly(vinylsulfonic acid, sodium salt) solutions were further characterized using the ESCA and TOF-SIMS techniques.

\section{Results and Discussion}

Table 1 shows the results of 4-point probe data for surface conductivities of both sides of oxidized PPy-PVS films, their thicknesses, and the variation of the concentration of pyrrole (from $0.1 \mathrm{~mole} \mathrm{~kg}^{-1}$ to 0.5 mole kg${ }^{-1}$ ) with $0.1 \mathrm{~mol} \mathrm{~kg}^{-1}$ of PVS. The surface conductivities, as measured using the 4point probe technique mentioned, for the electrolyte and electrode sides of each film were not significantly different between their surfaces. Surface conductivity increased with 


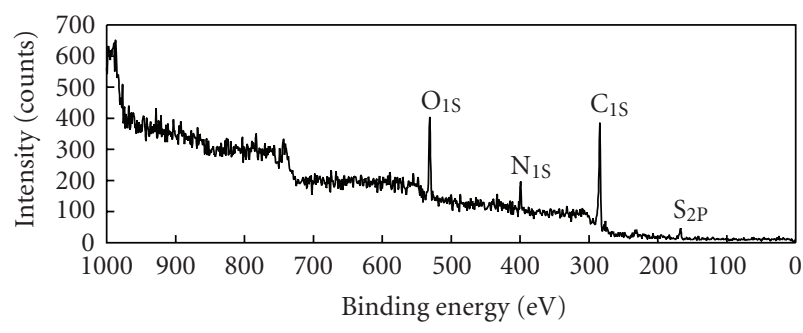

(a) The wide scan for PPy-PVS oxidised film at the electrolyte side

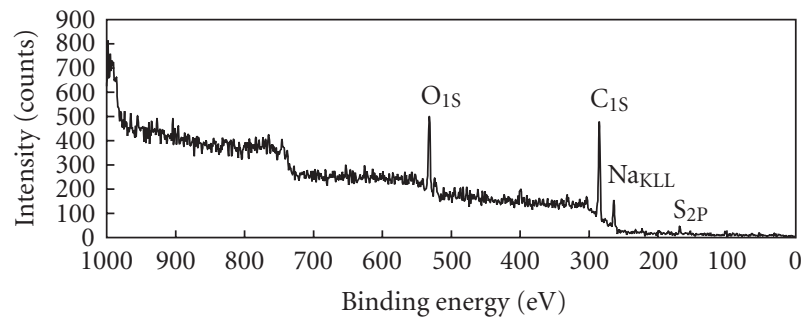

(c) The wide scan for PPy-PVS reduced film at the electrolyte side

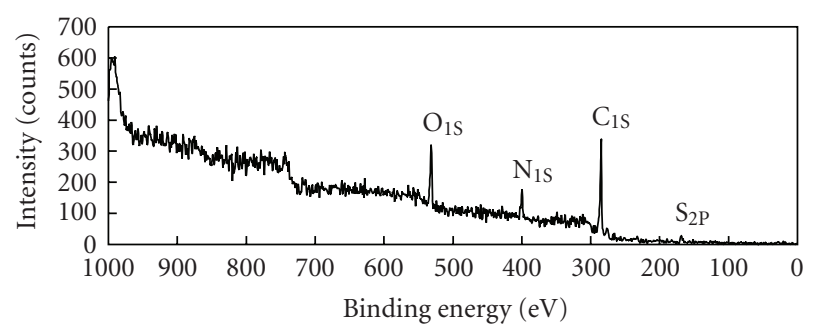

(b) The wide scan for Ppy-PVS oxidised film at the electrode side

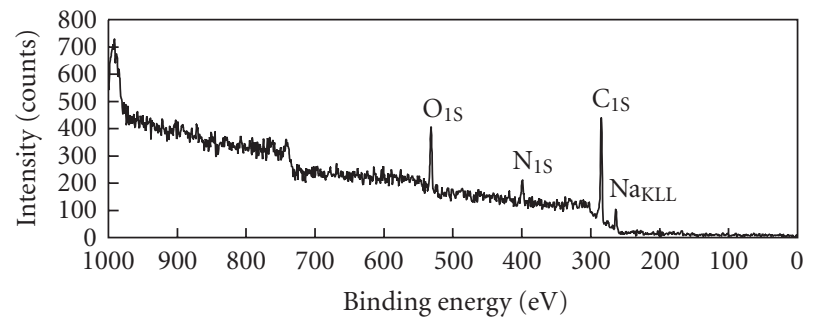

(d) The wide scan for PPy-PVS reduced film at the electrode side

Figure 1: The ESCA wide energy scans on (a) electrolyte (b) electrode sides of PPy-PVS oxidised film and (c) electrolyte (d) electrode sides of PPy-PVS reduced film.

TABle 2: Percentage of the various binding energies of elemental composite ( $\mathrm{C}-\mathrm{C}, \mathrm{C}=\mathrm{N}, \mathrm{CO}$, and $\mathrm{COOH})$ for PPy-PVS oxidised and reduced films of the film surfaces calculated from ESCA data, using values of atomic sensitivity factors (relative to C 1s), $\sigma_{i}[21]$.

\begin{tabular}{lcccc}
\hline $\begin{array}{l}\text { PPy/PVS film } \\
\text { Oxidised }\end{array}$ & $\mathrm{C}-\mathrm{C}$ & $\mathrm{C}-\mathrm{OH} / \mathrm{C}=\mathrm{N}$ (Binding energy $(\mathrm{eV}))$ & $\mathrm{CO}$ & $\mathrm{COOH}$ \\
$\quad$ (a) Electrolyte side & $72.3(284.6)$ & $19.7(286.2)$ & $8.0(287.8)$ & \\
$\quad$ (b) Electrode side & $71.0(284.8)$ & $19.1(286.2)$ & $9.8(287.6)$ & \\
\hline $\begin{array}{l}\text { Reduced } \\
\text { (a) Electrolyte side }\end{array}$ & $72.7(285.3)$ & $19.5(286.5)$ & $7.8(287.9)$ & $6.3(289.0)$ \\
(b) Electrode side & $75.2(285.1)$ & $15.7(286.3)$ & $9.1(287.6)$ & \\
\hline
\end{tabular}

increase in pyrrole (PPy) concentration in the forming solution, as shown in Table 1. The increase in PPy concentration will increase the formation of more conjugated polypyrrole chains, which in turn increase the electrical conductivity of the polymer film. Therefore, the conjugated system was the main factor in determining conductivity of the polymer film in this case. However, the films produced using $0.1 \mathrm{~mol} \mathrm{~kg}^{-1}$ of pyrrole were thicker than those films, with increase in concentration of pyrrole (from 0.2 mole kg-1 to 0.5 mole $\mathrm{kg}^{-1}$ ), as shown in Table 1 . It shows that morphology of $0.1 \mathrm{~mol} \mathrm{~kg}^{-1}$ of PPy-PVS free standing film is more stable and flexible as compared to those films with increase in concentration of pyrrole (that are more brittle). As the good conductivity was observed with the increase in concentration of pyrrole for this polymer films, the authors urge that further investigation should be made to resolve its inadequacy when applied to study such polymers.

Furthermore, we studied 0.1 mole $\mathrm{kg}^{-1}$ of pyrrole in oxidized and reduced PPy-PVS free standing films using ESCA. The ESCA wide scans on electrolyte (side facing solution) and electrode (side facing metal) of PPy-PVS oxidised and reduced films are show in Figure 1. It was observed that the $S_{2 P}$ core-level signal $(\sim 163 \mathrm{eV})[21]$ was decreased at the electrode side compared to the electrolyte side of PPy-PVS oxidised film. Obviously, the $\mathrm{N}_{1 \mathrm{~S}}$ corelevel signal $(\sim 399 \mathrm{eV})$ was higher at the electrolyte compared to the electrode side of PPy-PVS reduced film and thus explained by following TOF-SIMS technique (Figures 5(c) and 5(d)). The $\mathrm{S}_{2 \mathrm{P}}$ signal almost disappeared at the electrode side but it was found in the electrolyte side of PPy-PVS reduced film as shown in Figures 1(c) and 1(d). The final noteworthy features of ESCA wide scans are the Auger NaKLL core-level signal about $264 \mathrm{eV}$ only found in electrolyte and electrode sides of the reduced PPy-PVS film. The auger NaKLL couldnot found in oxidised PPy-PVS film.

Figures 2(a) to 2(d) indicated the C (1s) spectra obtained using ESCA, the four components are respectively attributed to the neutral carbons $(\sim 284.5 \mathrm{eV}), \mathrm{C}-\mathrm{OH}$ or $\mathrm{CN}$ structures $(\sim 286 \mathrm{eV})$, CO structures $(\sim 287.7 \mathrm{eV})$, and $\mathrm{COOH}$ structures $(\sim 288.9 \mathrm{eV})[13,18,21,22]$. Table 2 summarised the results of the percentage of different types of carbon using the equation arisen in our earlier paper [1] that is used in 


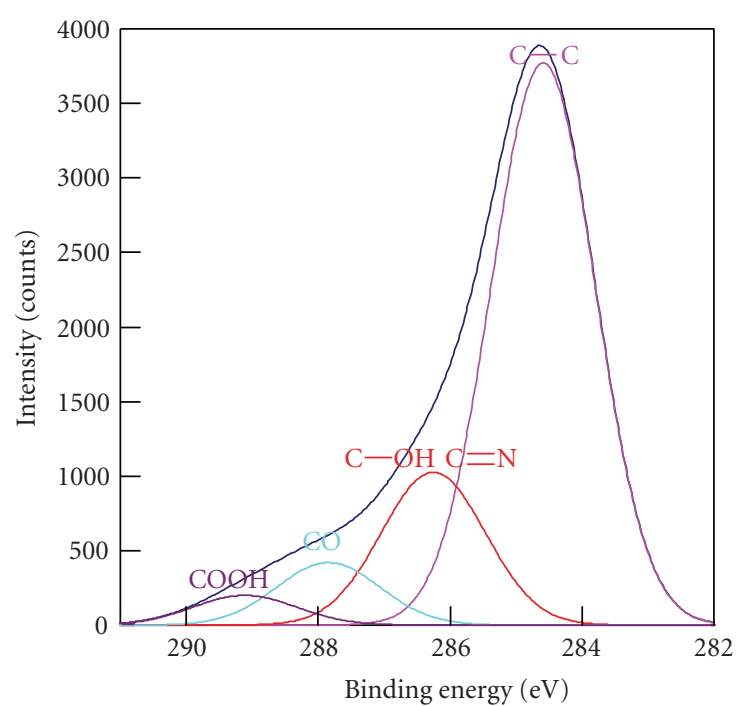

(a)

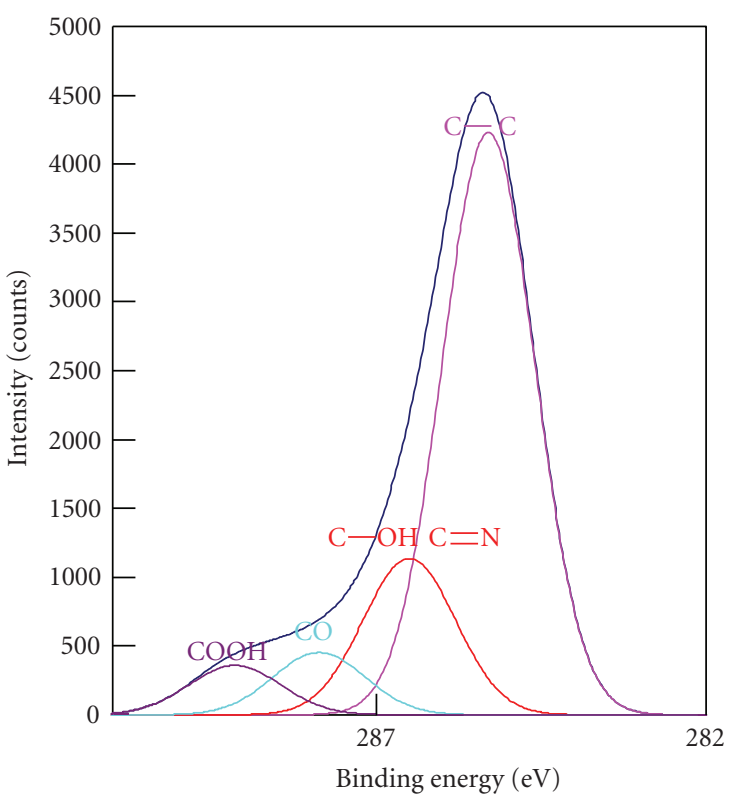

(c)

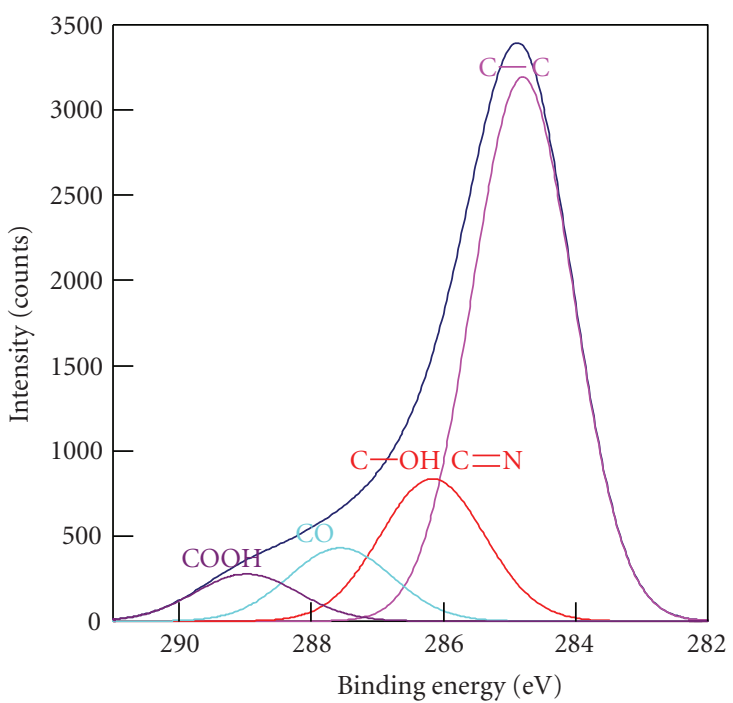

(b)

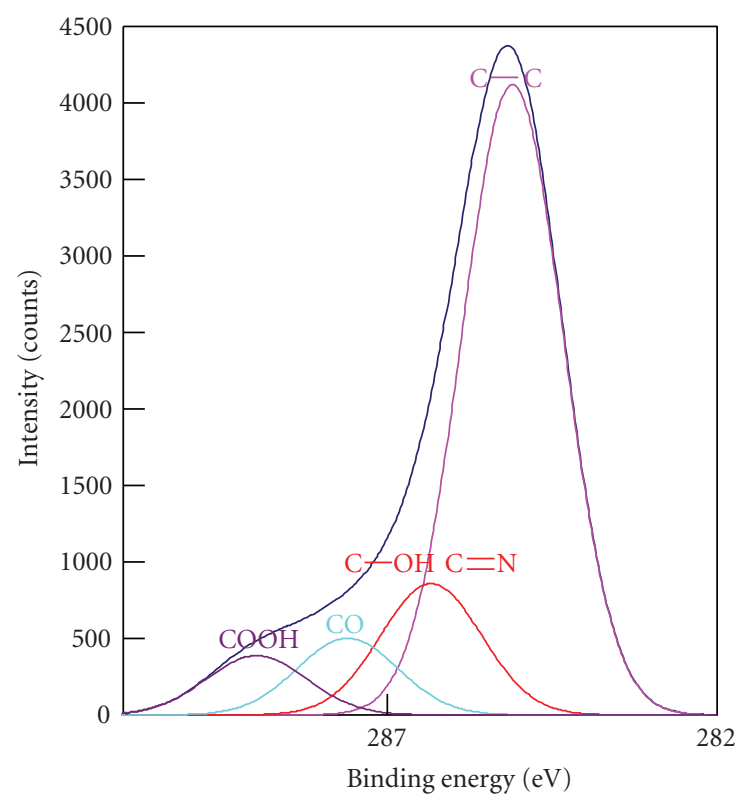

(d)

FIGURE 2: C 1s core-level spectra's (a) electrolyte (b) electrode sides of PPy-PVS oxidised film and (c) electrolyte (d) Electrode sides of PPy-PVS reduced film.

present studies on PPy-PVS films. It was shown that the CO structures were slightly higher at the electrode $(9.8 \%)$ compared to the electrolyte (8.0\%) sides of the oxidised PPyPVS free standing films. However, the $(\mathrm{C}-\mathrm{OH})$ structures are slightly lower at the electrode $(19.1 \%)$ compared to the electrolyte (19.7\%) sides of the oxidised PPy-PVS films. The slight percentage difference between the electrolyte and electrode of oxidised PPy-PVS is probably due to the more positive charges received at electrode compared to electrolyte sides during electropolymerization process. These results are in conformity with the results arised by Ge et al. [13]. They reported that carbons are oxidized into $\mathrm{C}-\mathrm{OH}$ and sub- sequently changed into $\mathrm{C}=\mathrm{O}$ during overoxidation $(>0.9 \mathrm{~V}$ versus $\mathrm{Ag} / \mathrm{AgCl}$ ) [13]. However, after applying the reduction potential $(-1.0 \mathrm{~V})$, the percentages of $\mathrm{CO}$ structures were slightly lower at the electrode $(9.1 \%)$ and electrolyte $(7.8 \%)$ sides of the reduced PPy-PVS film compared to oxidised $\mathrm{PPy} / \mathrm{PVS}$ film. The $\mathrm{C}-\mathrm{OH}$ structures are slightly lower at the electrode $(15.7 \%)$ and electrolyte $(19.5 \%)$ sides of the reduced PPy-PVS film compared to oxidised PPy-PVS film. It was found that the percentages of $\mathrm{C}-\mathrm{C}$ bonds are increased (from $72.3 \%$ to $72.7 \%$ at electrolyte and $71.0 \%$ to $75.2 \%$ at electrode) when the reduction potential is applied. It can be concluded that $\mathrm{C}-\mathrm{C}$ bonds oxidised to $\mathrm{CO}$ and $\mathrm{C}-\mathrm{OH}$ 


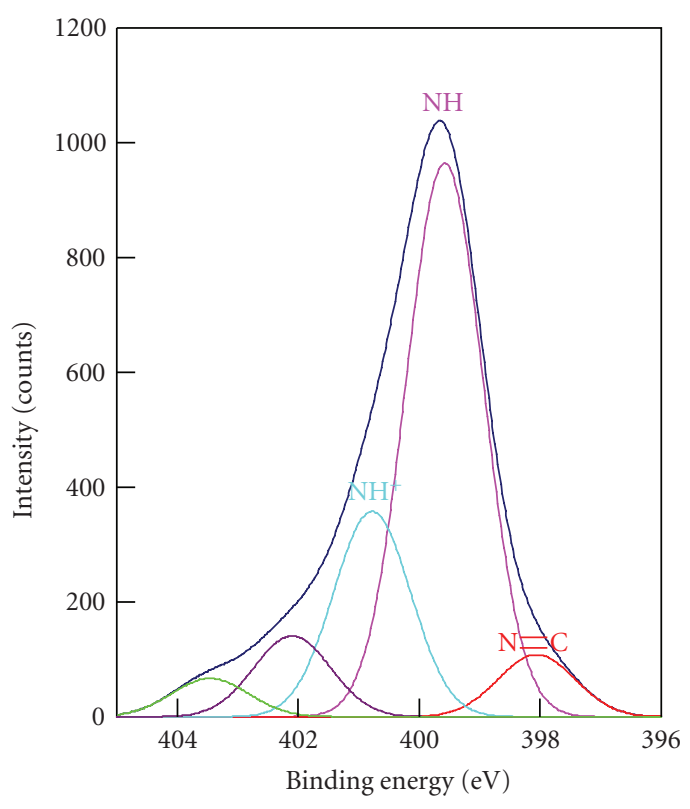

(a)

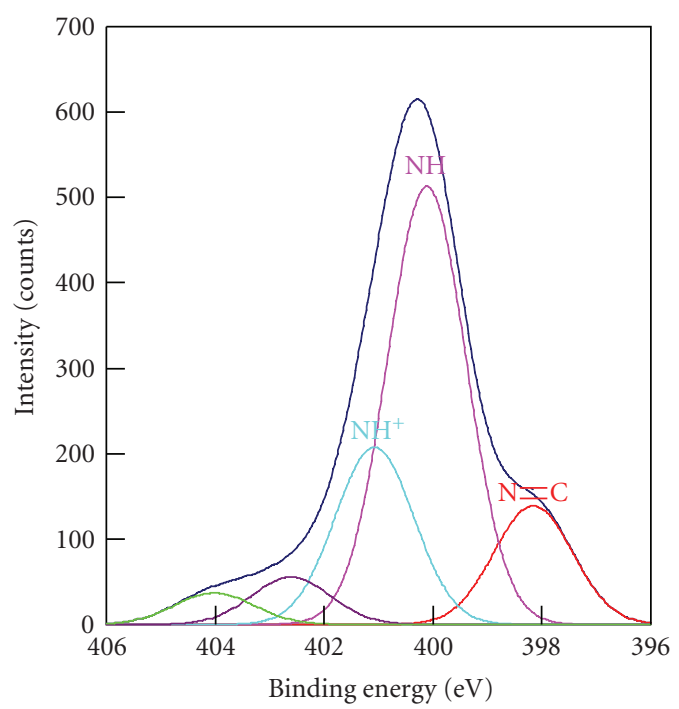

(c)

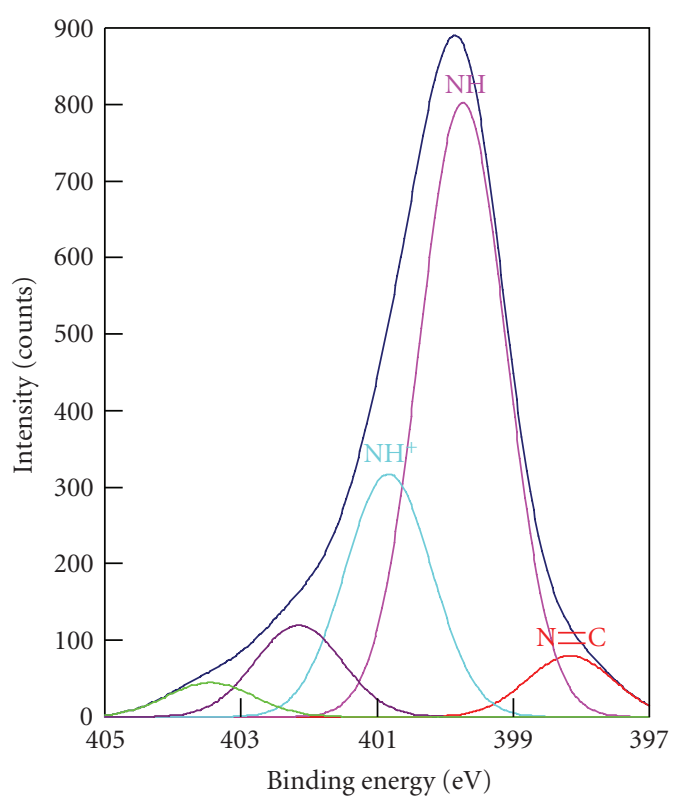

(b)

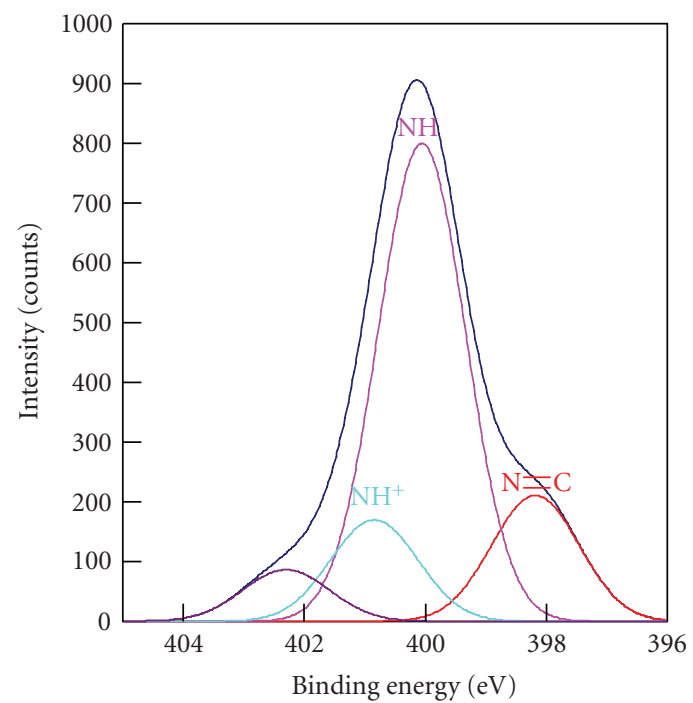

(d)

Figure 3: N 1s core-level spectra's (a) electrolyte (b) electrode sides of PPy-PVS oxidised film and (c) electrolyte (d) electrode sides of PPy-PVS reduced film.

structures during overoxidation (1.6-2.3 V). Consequently, the $\mathrm{CO}$ and $\mathrm{C}-\mathrm{OH}$ structures slightly reduced to $\mathrm{C}-\mathrm{C}$ bonds during reduction process.

Figures 3(a) and 3(b) show the respective $\mathrm{N} 1 \mathrm{~s}$ corelevel spectra for PPy-PVS oxidised film and Figures 3(c) and 3(d) observe $\mathrm{N}$ 1s spectra for PPy-PVS reduced films. Figures 3(a) to 3(c) of the peaks are fitted with five respective components that are attributable to the imine $\mathrm{N}=\mathrm{C} \operatorname{group}(\sim$ $398 \mathrm{eV})$, the $\mathrm{N}-\mathrm{H}$ bond in pyrrole repeated unit $(\sim 400 \mathrm{eV})$, the positively charged nitrogen $\left(\mathrm{NH}^{+}\right)(\sim 401 \mathrm{eV})$, and the two high oxidation states of nitrogen $(\geq 402 \mathrm{eV})$ in doped polypyrrole [21]. However in part (d) of Figure 3, the peaks are shown in imine group $(\mathrm{N}=\mathrm{C}), \mathrm{N}-\mathrm{H}$ bond, $\mathrm{NH}^{+}$, and one of high oxidation states of nitrogen. We summarised the results of Figure 3 of $\mathrm{N}$ 1s peak of PPy-PVS oxidised and reduced films in Table 3 . Table 3 shows that the amount of $\mathrm{N}-\mathrm{H}$ bonds decreased significantly (from $67.3 \%$ to $59.5 \%$ ) at the electrolyte side of PPy-PVS film after reduction potential was applied. After reduction process, the imine group $(\mathrm{N}=\mathrm{C})$ was increased ( $7.6 \%$ to $16.3 \%$ at electrolyte side and $6.7 \%$ to $17.6 \%$ at electrode side) while $\mathrm{NH}^{+}$decreased (25.1\% to $24.2 \%$ at electrolyte side and $26.6 \%$ to $14.5 \%$ at electrode side) for reduced film. Ge et al. [13] presented the replacement of some $\mathrm{NH}^{+}$centres of PPY by $\mathrm{N}-\mathrm{H}$ during 


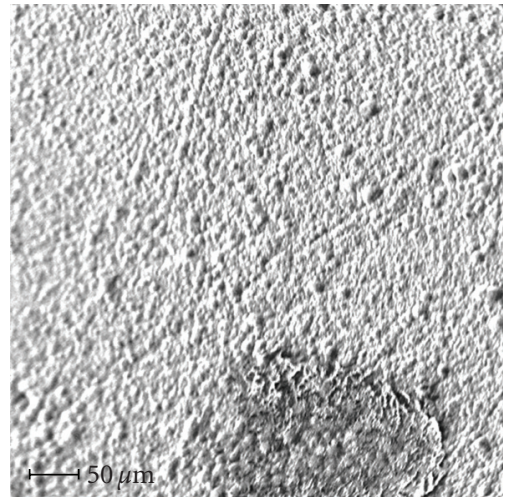

(a)

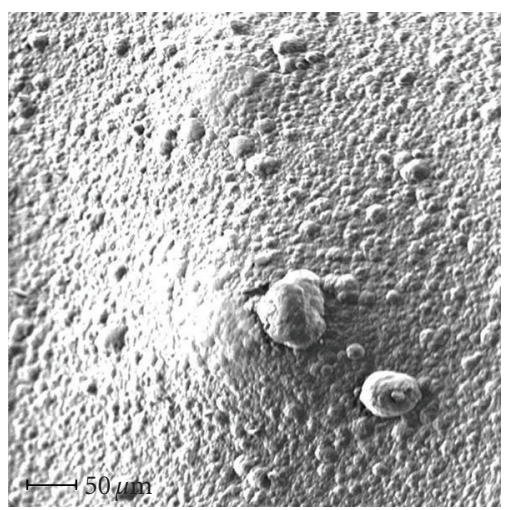

(c)

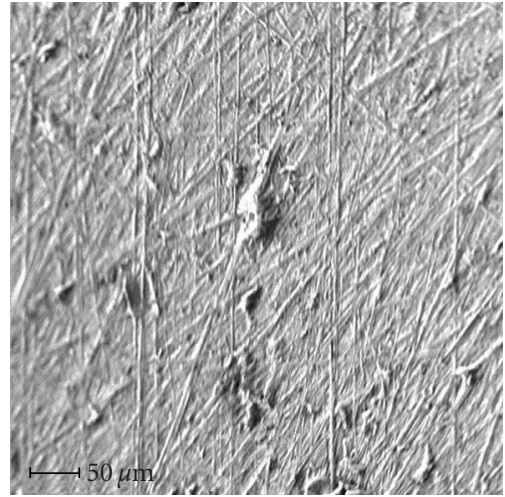

(b)

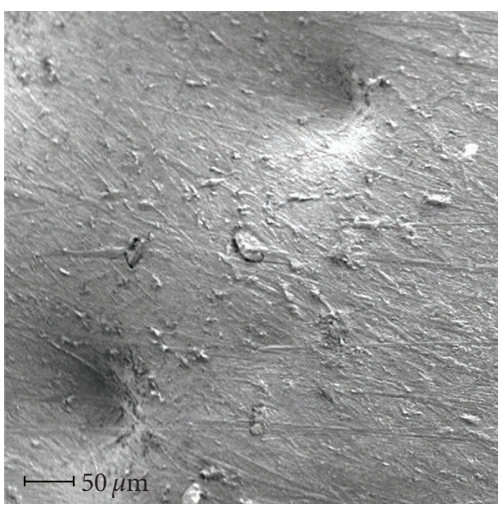

(d)

FIGURE 4: Secondary electron image of the surface (a) electrolyte (b) electrode sides of PPy-PVS oxidised film and (c) electrolyte (d) electrode sides of PPy-PVS reduced film.

TABLE 3: Percentage of the various binding energies of elemental composite $\left(\mathrm{N}=\mathrm{C}, \mathrm{NH}\right.$, and $\left.\mathrm{NH}^{+}\right)$for PPy-PVS oxidised and reduced films of the film surfaces calculated from ESCA data, using values of atomic sensitivity factors (relative to C 1s), $\sigma_{i}$ [21].

\begin{tabular}{lccc}
\hline & \multicolumn{3}{c}{$\%$ (Binding energy $(\mathrm{eV}))$} \\
PPy/PVS film & $\mathrm{N}=\mathrm{C}$ & $\mathrm{NH}$ & $\mathrm{NH}^{+}$ \\
\hline Oxidised & & & \\
(a) Electrolyte side & $7.6(398.1)$ & $67.3(399.6)$ & $25.1(400.8)$ \\
(b) Electrode side & $6.7(398.2)$ & $66.7(399.7)$ & $26.6(400.8)$ \\
\hline Reduced & & & \\
(a) Electrolyte side & $16.3(398.2)$ & $59.5(400.1)$ & $24.2(401.1)$ \\
(b) Electrode side & $17.8(398.2)$ & $67.7(400.1)$ & $14.5(400.8)$ \\
\hline
\end{tabular}

overoxidation state. However, we found that the $\mathrm{NH}^{+}$and $\mathrm{N}-\mathrm{H}$ (at electrolyte side) bonds are reduced to imine group $(\mathrm{N}=\mathrm{C})$ during reduction process.

Furthermore, the secondary electron images on the surface of PPy-PVS oxidised and reduced films derived from TOF-SIMS technique are shown in Figures 4 and 5. It was shown that the surface morphology at the electrode of the PPy-PVS oxidised film (Figure 4(b)) was more uniform surface than the electrolyte side (Figure 4(a)). In reduced PPy-PVS film (Figure $4(\mathrm{c})$ ), a rough surface was observed at the electrolyte side. This indicated that the reorganization process occurred during the reduction process. Figure $4(\mathrm{~d})$ shows the two holes observed at surface of PPy-PVS reduced electrode side, which is due to measurement of four-point probe. Figure 5(a) presented the TOF-SIMS ion distribution maps for various selected species (e.g., $\mathrm{H}, \mathrm{C}, \mathrm{NH}, \mathrm{O}, \mathrm{OH}$, $\mathrm{C}_{2}, \mathrm{CN}$, and $\mathrm{S}$ ) at the electrolyte side of PPy-PVS oxidised film. The brightest and lightest colour intensity corresponds to the highest surface concentration of ions on the surface. It was found that the intensity of the $\mathrm{CN}$ and $\mathrm{C}_{2}$ elements was higher than that of other elements (e.g., $\mathrm{S}$ or $\mathrm{O}$ ) at electrode side and greater than that at electrolyte side as shown in Figures 5(a) and 5(b). This indicated that the amounts of polypyrrole were greater at the electrode side, giving a uniform surface of oxidised PPy-PVS film (Figure 4(b)). Consequently, the distribution of the elements $\mathrm{CN}$ and $\mathrm{S}$ appeared to be the same at the electrolyte side of the reduced PPy-PVS film (Figure 5(c)). However, the intensity of the $\mathrm{CN}$ element was substantially higher than the intensity of $\mathrm{S}$ at the electrode side of the PPy-PVS reduced film (Figure 5(d)), leading to the conclusion that PVS anions were more in the electrolyte side surface than the electrode side surface, giving a rough surface of reduced PPy-PVS film (Figure 4(c)). Possible explanation for the presence of trace amounts of $\mathrm{CN}$ and $\mathrm{S}$ is that molecules pyrrole has formed 


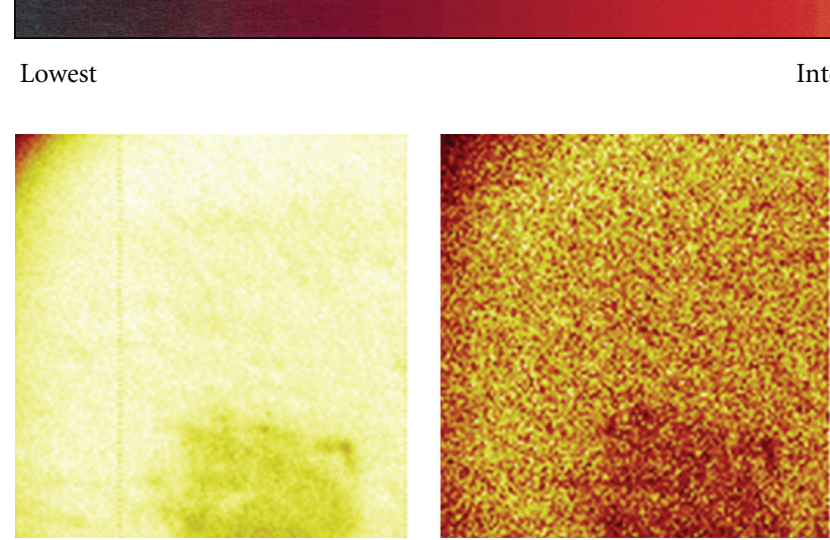

$\mathrm{H}$

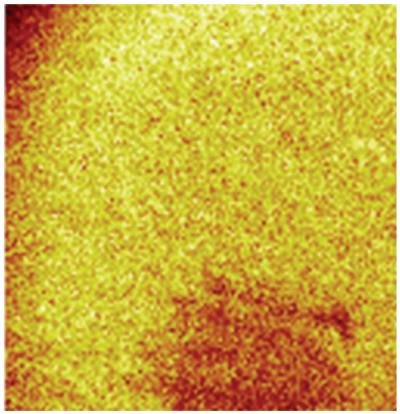

$\mathrm{OH}$

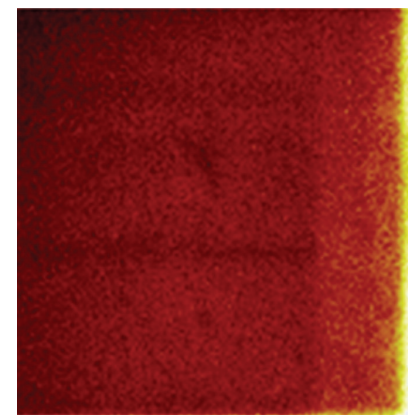

H

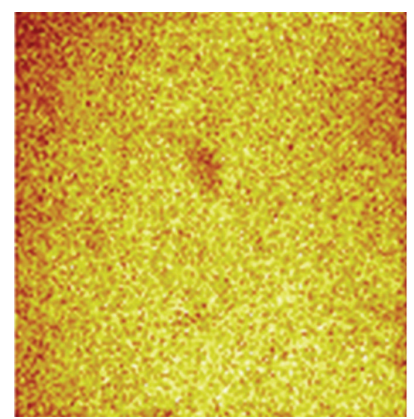

$\mathrm{C}_{2}$

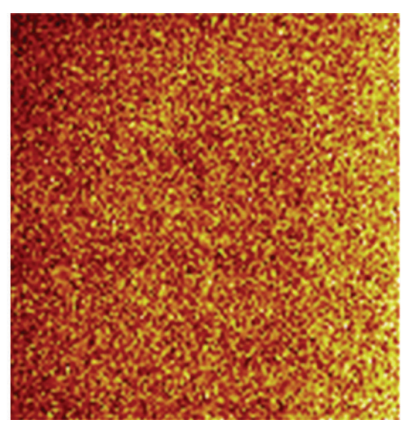

C

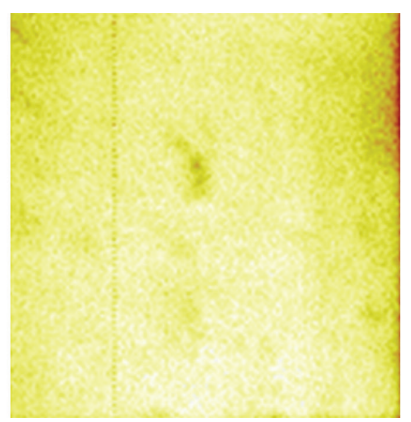

$\mathrm{CN}$
Intensity

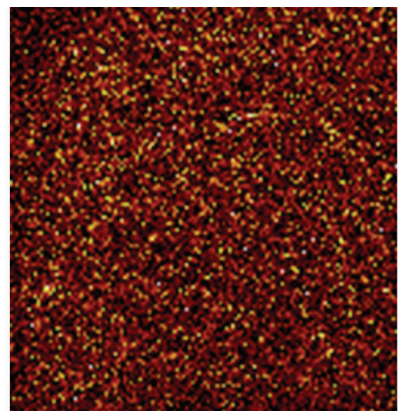

$\mathrm{NH}$

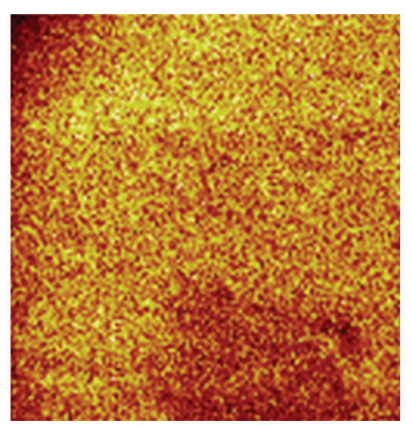

$\mathrm{C}_{2}$

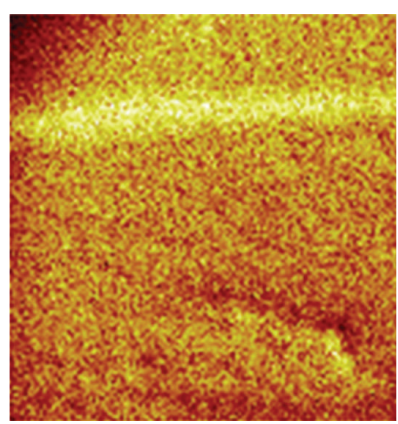

$\mathrm{CN}$

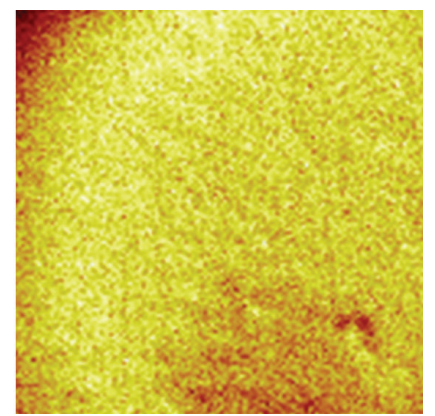

$\mathrm{O}$

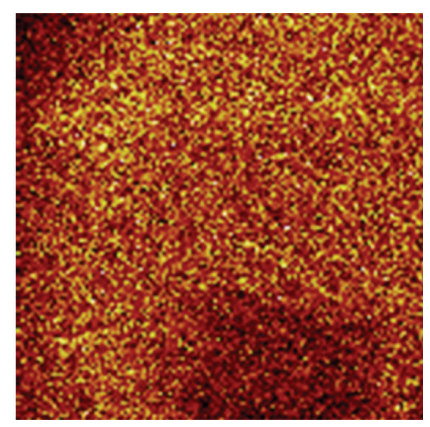

S

(a)

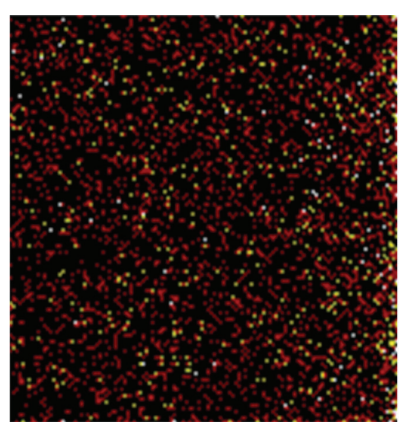

$\mathrm{NH}$

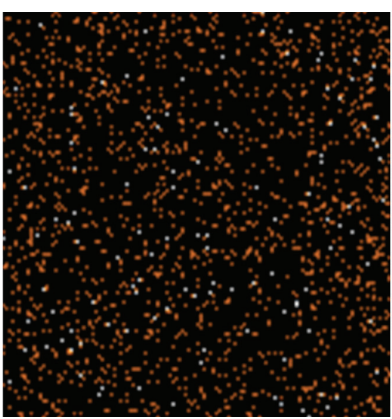

NO

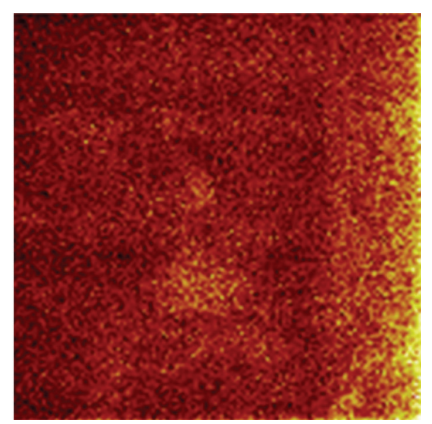

$\mathrm{O}$

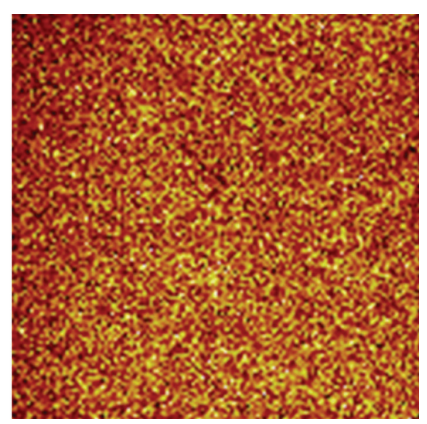

S

(b)

Figure 5: Continued. 
Lowest

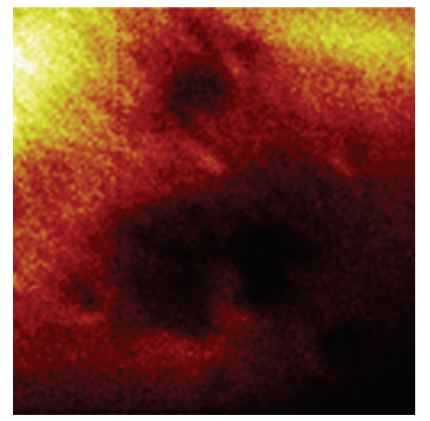

$\mathrm{O}$

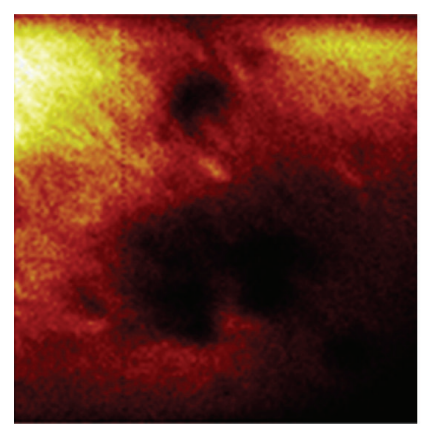

S

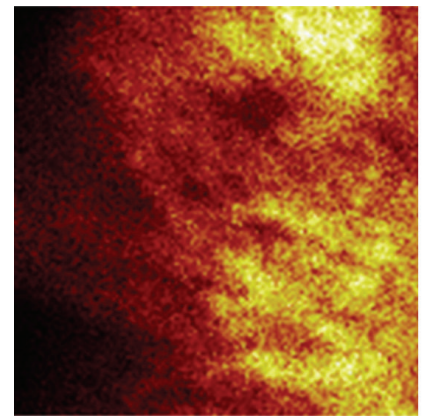

O

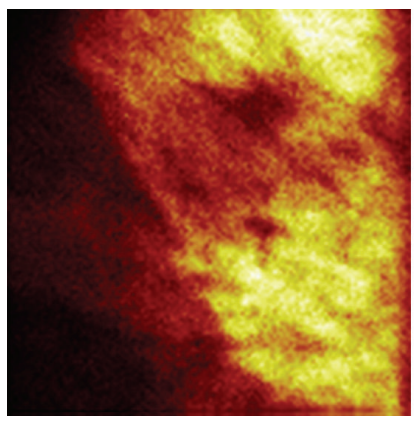

S
Intensity

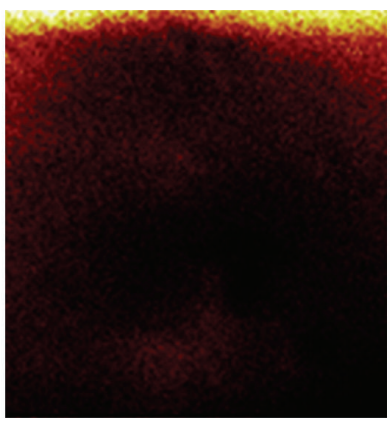

$\mathrm{OH}$

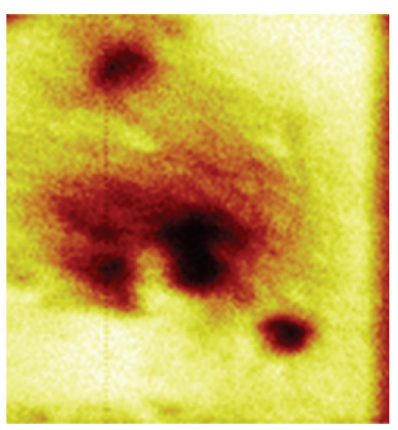

$\mathrm{Na}$

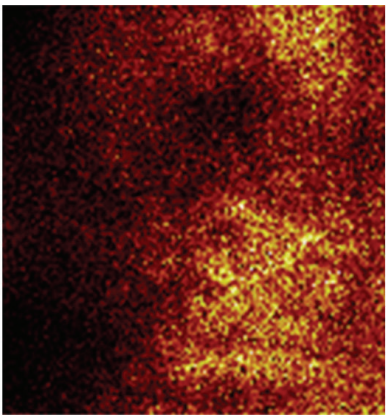

$\mathrm{OH}$

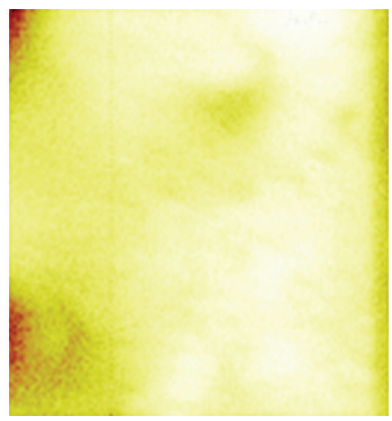

$\mathrm{M}: 23(\mathrm{Na})$

(c)

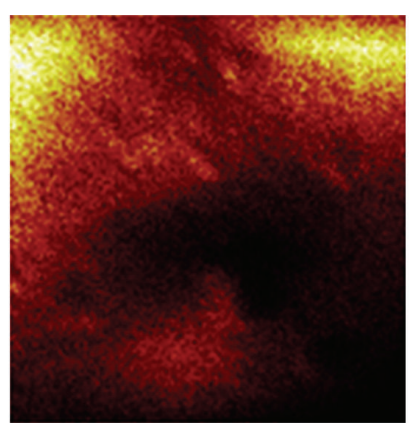

$\mathrm{C}_{2}$

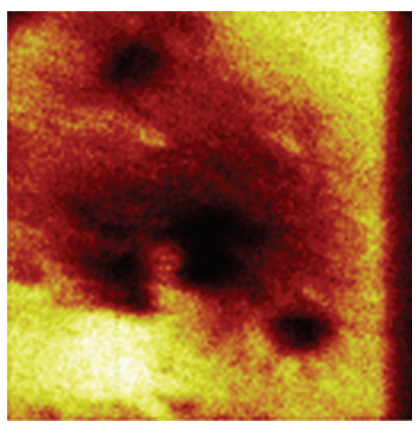

K

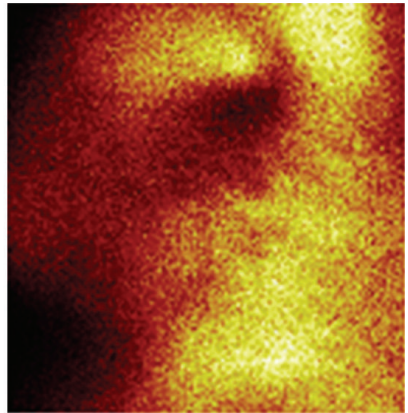

$\mathrm{C}_{2}$

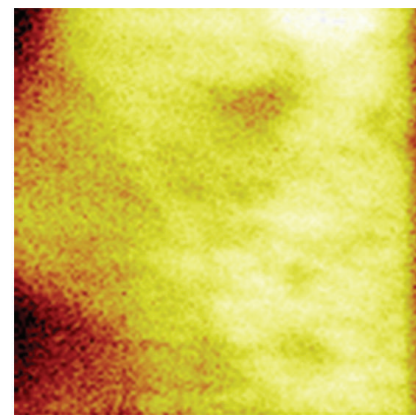

$\mathrm{M}: 39(\mathrm{~K})$

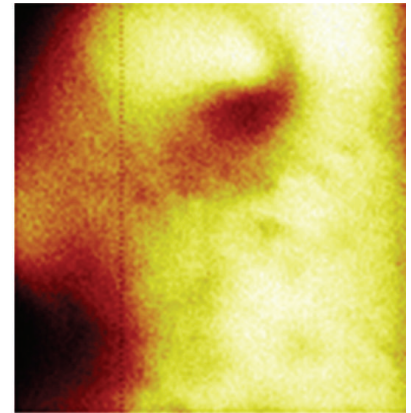

$\mathrm{CN}$
Highest

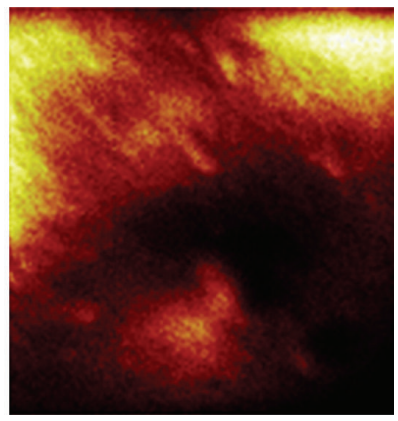

CN

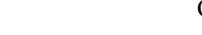


polypyrrole film at electrode side during oxidation process, but the negative charged PVS ${ }^{-}$has trapped PPy film, were not completely balanced only by the positive charged centres of PPy as reported in our previous studies [1]. The $\mathrm{Na}$ and $\mathrm{K}$ were more evenly distributed than $\mathrm{O}, \mathrm{OH}, \mathrm{C}_{2}, \mathrm{CN}$, and $\mathrm{S}$ as shown in Figure 5(c). The incorporation of $\mathrm{Na}$ (from the PVS solution) and $\mathrm{K}$ (from the $\mathrm{KCl}$ of $\mathrm{Ag} / \mathrm{AgCl}$ reference electrode) was balanced by the immobilised charges of the reduced PPy/PVS film. Similar appearance was also shown in electrode side of the PPy/PVS reduced film (Figure 5(d)) and thus explained by previously ESCA wide scan (Figure 1).

\section{Conclusions}

The surface conductivities of the PPy/PVS films were in the range from 0.018 to $0.062 \mathrm{~S} / \mathrm{cm}$. The variation was due to the variation in concentration of pyrrole used (in the range 0.1 to 0.5 mole $\mathrm{kg}^{-1}$ ). From the results obtained, it can be concluded that the electrical conductivity of the polymer film was largely dependent on the conjugated polypyrrole chains. It was shown that there is no significant difference in surface conductivities between the electrolyte sides and the electrode sides. ESCA spectra revealed the slight changes of $\mathrm{CO}$ and $\mathrm{C}-\mathrm{OH}$ structures to $\mathrm{C}-\mathrm{C}$ bonds during reduction process. The ESCA results also show the charge transfer behavior of the deprotonation of pyrrolium nitrogen $\left(\mathrm{NH}^{+}\right)$and $\mathrm{N}-$ $\mathrm{H}$ bonds to imine group $(\mathrm{N}=\mathrm{C})$ at reduced PPy-PVS free standing film. It was found from secondary ion mapping that there were more PVS anions on the electrolyte side of the reduced PPy-PVS film that give a rough surface at reduced film. However, the more $\mathrm{CN}$ and $\mathrm{C}_{2}$ elements (polypyrrole chain) were attributed the fine the surface of oxidised PPyPVS film. The insertion of monovalent cations ( $\mathrm{Na}$ or $\mathrm{K}$ ) into the PPy-PVS film was found in reduced PPy-PVS film.

\section{Acknowledgments}

The authors would like to thank the University of Malaya for financial support and Mr. L.H. Soo of AMCAL for technical assistance. An IRPA Grant from the Malaysian Government is gratefully acknowledged.

\section{References}

[1] S.-L. Sin, L.-L. Teo, K.-S. Tan, and C.-Y. Chan, "ESCA and TOF-SIMS study on oxidised and reduced polypyrrolepoly(4-styrenesulfonate) free-standing films synthesized on $\mathrm{Ti}$ electrodes," Electrochemistry Communications, vol. 2, no. 10, pp. 685-691, 2000.

[2] V. K. Gade, D. J. Shirale, P. D. Gaikwad, et al., "Synthesis and characterization of Ppy-PVS, P(NMP)-PVS and their copolymer Ppy-P(NMP)-PVS films by galvanostatic method," International Journal of Electrochemcal Science, vol. 2, pp. 270277, 2007.

[3] S. Chao and M. S. Wrighton, "Solid-state microelectrochemistry: electrical characteristics of a solid-state microelectrochemical transistor based on poly(3-methylthiophene)," Journal of the American Chemical Society, vol. 109, no. 7, pp. 2197-2199, 1987.
[4] L. W. Shacklette, R. R. Chance, D. M. Ivory, G. G. Miller, and R. H. Baughman, "Electrical and optical properties of highly conducting charge-transfer complexes of poly(p-phenylene)," Synthetic Metals, vol. 1, no. 3, pp. 307-320, 1980.

[5] L. H. M. Krings, E. E. Havinga, J. J. T. M. Donkers, and F. T. A. Vork, "The application of polypyrrole as counterelectrode in electrolytic capacitors," Synthetic Metals, vol. 54, no. 1-3, pp. 453-460, 1993.

[6] H. H. Kuhn, R. V. Gregory, and W. C. Kimbrell, "Conductive textile composites," in Proceedings of the $3 r$ International SAMPE Electronics Conference: Electronic Materials and Processes, vol. 3, pp. 570-577, Los Angeles, Calif, USA, June 1989.

[7] M. D. Imisides, R. John, P. J. Reiley, and G. G. Wallace, "The use of electropolymerization to produce new sensing surfaces: a review emphasizing electrode position of heteroaromatic compounds," Electroanalysis, vol. 3, no. 9, pp. 879-889, 1991.

[8] T. Lindfors, J. Bobacka, A. Lewenstam, and A. Ivaska, "Study on soluble polypyrrole as a component in all-solid-state ionsensors," Electrochimica Acta, vol. 43, no. 23, pp. 3503-3509, 1998.

[9] T. L. Lian, An electrochemical study of polypyrrole based composite polymers and their applications, M.S. thesis, University of Malaya, Kuala Lumpur, Malaysia, 1999.

[10] T. Shimidzu, A. Ohtani, and K. Honda, "Charge-controllable poly pyrrole/poly electrolyte composite membranes_-part III: electrochemical deionization system constructed by anionexchangeable and cation-exchangeable polypyrrole electrodes," Journal of Electroanalytical Chemistry, vol. 251, no. 2, pp. 323-337, 1988.

[11] V. K. Gade, D. J. Shirale, P. D. Gaikwad, et al., "Immobilization of GOD on electrochemically synthesized Ppy-PVS composite film by cross-linking via glutaraldehyde for determination of glucose," Reactive and Functional Polymers, vol. 66, no. 12, pp. 1420-1426, 2006.

[12] A. Gambhir, M. Gerard, S. K. Jain, and B. D. Malhotra, "Characterization of DNA immobilized on electrochemically prepared conducting polypyrrole-polyvinyl sulfonate films," Applied Biochemistry and Biotechnology, vol. 96, no. 1-3, pp. 303-311, 2001.

[13] H. Ge, G. Qi, E.-T. Kang, and K. G. Neoh, "Study of overoxidized polypyrrole using X-ray photoelectron spectroscopy," Polymer, vol. 35, no. 3, pp. 504-508, 1994.

[14] E. T. Kang, K. G. Neoh, Y. K. Ong, K. L. Tan, and B. T. G. Tan, "X-ray photoelectron spectroscopy studies of deprotonated polypyrrole and its complexes," Polymer, vol. 32 , no. 8, pp. 1354-1360, 1991.

[15] P. Pfluger and G. B. Street, "Chemical, electronic, and structural properties of conducting heterocyclic polymers: a view by XPS," The Journal of Chemical Physics, vol. 80, no. 1, pp. 544-553, 1984.

[16] E. T. Kang, K. G. Neoh, and K. L. Tan, "Conductive polymers: spectroscopy and physical properties," in Handbook of Organic Conductive Molecules and Polymers, vol. 3, Wiley, Chichester, 1997.

[17] T. A. Skotheim, M. I. Florit, A. Melo, and W. E. O'Grady, "Ultrahigh-vacuum in situ electrochemistry with solid polymer electrolyte and X-ray photoelectron spectroscopy studies of polypyrrole," Physical Review B, vol. 30, no. 8, pp. 48464849, 1984.

[18] C. Perruchot, M. M. Chehimi, M. Delamar, S. F. Lascelles, and S. P. Armes, "Surface characterization of polypyrrole-coated polystyrene latex by X-ray photoelectron spectroscopy," Langmuir, vol. 12, no. 13, pp. 3245-3251, 1996. 
[19] M. C. Davies, R. A. P. Lynn, S. S. Davis, et al., "The surface chemical analysis of a series of persulfate-initiated chargestabilized poly(butyl methacrylate) latices using XPS and static SIMS," Journal of Colloid And Interface Science, vol. 156, no. 1, pp. 229-239, 1993.

[20] F. M. Smits, "Measurement of Sheet Resistivities with the Four-Point Probe," Bell System Technical Journal, vol. 37, p. $711,1958$.

[21] W. M. Riggs and M. J. Parker, in Methods of Surface Analysis, A. W. Czanderna, Ed., chapter 4, Elsevier, Amsterdam, The Netherlands, 1975.

[22] M. R. Josep, D. Amadou, M. T. Josep, and D. Bloor, "Chemical structure of polypyrrole: X-ray photoelectron spectroscopy of polypyrrole with 5-yliden-3-pyrrolin-2-one end groups," Polymer, vol. 32, no. 4, pp. 728-732, 1991. 

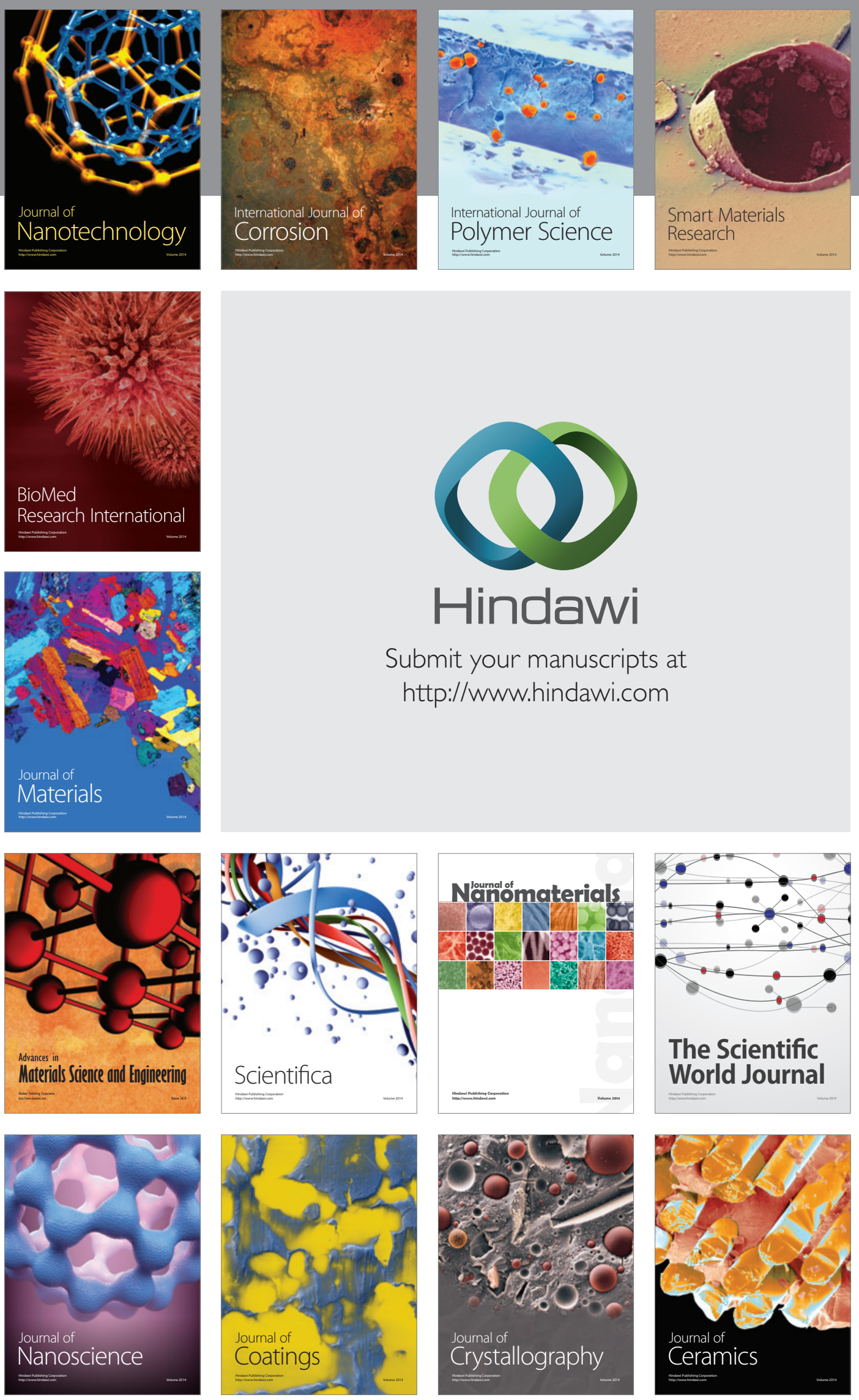

The Scientific World Journal

Submit your manuscripts at

http://www.hindawi.com

\section{World Journal}

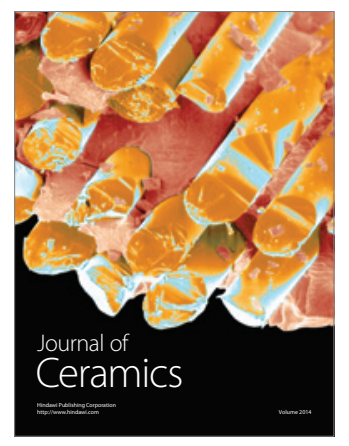

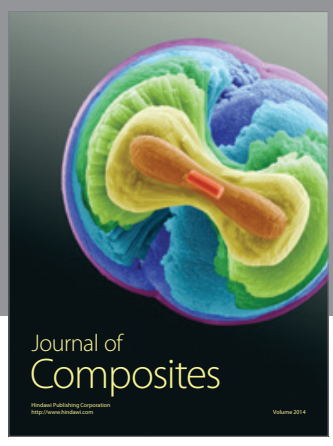
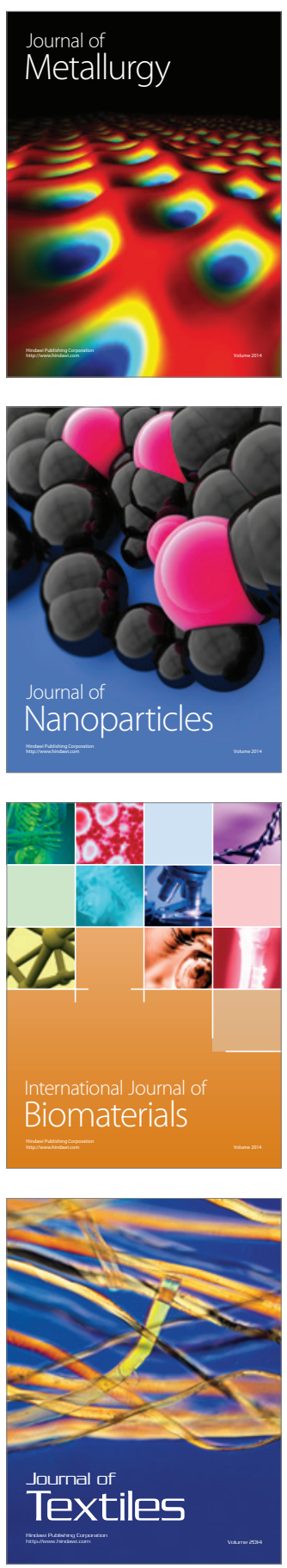